Article

\title{
The Prognostic Roles of Pretreatment Circulating Tumor Cells, Circulating Cancer Stem-Like Cells, and Programmed Cell Death-1 Expression on Peripheral Lymphocytes in Patients with Initially Unresectable, Recurrent or Metastatic Head and Neck Cancer: An Exploratory Study of Three Biomarkers in One-time Blood Drawing
}

\author{
Pei-Hung Chang 1,2,3,4 ${ }^{D}$, Min-Hsien Wu 4,5,6, Sen-Yu Liu 1,4 , Hung-Ming Wang 1,4, \\ Wen-Kuan Huang 1,7, Chun-Ta Liao 1,4,8, Tzu-Chen Yen 1,9,10, Shu-Hang Ng 1,11,12, \\ Jen-Shi Chen 1,4 (D), Yung-Chang Lin ${ }^{1,4}$, Hung-Chih Lin ${ }^{1,4}$ and Jason Chia-Hsun Hsieh ${ }^{1,4, *}$ \\ 1 Chang Gung University, College of Medicine, Taoyuan 333, Taiwan; ph555chang@cgmh.org.tw (P.-H.C.); \\ n820903@gmail.com (S.-Y.L.); whm526@adm.cgmh.org.tw (H.-M.W.); medfoxtaiwan@gmail.com (W.-K.H.); \\ Liaoct@adm.cgmh.org.tw (C.-T.L.); Yen1110@adm.cgmh.org.tw (T.-C.Y.); shng@adm.cgmh.org.tw (S.-H.N.); \\ js1101@cgmh.org.tw (J.-S.C.); yclinof@cgmh.org.tw (Y.-C.L.); sangerhj@gmail.com (H.-C.L.) \\ 2 Division of Hematology-Oncology, Department of Internal Medicine, Chang Gung Memorial Hospital, \\ Keelung 20401, Taiwan \\ 3 Cancer Center, Chang Gung Memorial Hospital, Keelung 20401, Taiwan \\ 4 Circulating Tumor Cell Lab, Division of Hematology-Oncology, Department of Internal Medicine, \\ Chang Gung Memorial Hospital, Linkuo 333, Taiwan; mhwu@mail.cgu.edu.tw \\ 5 Graduate Institute of Biochemical and Biomedical Engineering, Chang Gung University, \\ Taoyuan 333, Taiwan \\ 6 Department of Chemical Engineering, Ming Chi University of Technology, New Taipei City 24301, Taiwan \\ 7 Department of Oncology-Pathology, Karolinska Institutet, Stockholm, Sweden; Cancer Center Karolinska, \\ Karolinska University Hospital, SE-17176 Stockholm, Sweden \\ 8 Department of Otorhinolaryngology, Head and Neck Surgery, Chang Gung Memorial Hospital and Chang \\ Gung University, Taoyuan 333, Taiwan \\ 9 Molecular Imaging Center, Linkou Chang Gung Memorial Hospital and Chang Gung University, \\ Taoyuan 333, Taiwan \\ 10 Department of Nuclear Medicine, Linkou Chang Gung Memorial Hospital and Chang Gung University, \\ Taoyuan 333, Taiwan \\ 11 Department of Diagnostic Radiology, Linkou Chang Gung Memorial Hospital and Chang Gung University, \\ Taoyuan 333, Taiwan \\ 12 Department of Medical Imaging and Radiological Sciences, Chang Gung Memorial Hospital, Chang Gung \\ University, Taoyuan 333, Taiwan \\ * Correspondence: wisdom5000@gmail.com; Tel.: +886-3-3281200 (ext. 8825)
}

Received: 21 February 2019; Accepted: 8 April 2019; Published: 15 April 2019 
$p=0.003$ ). A CD8 ${ }^{+}$proportion of $\geq 17 \%$ was associated with improved OS (HR: $0.242, p=0.004$ ). A CD4: CD8 ratio of $>1.2$ was associated with poorer trend of PFS (HR: 2.12, $p=0.064$ ). PD-1 expression was not associated with survival outcomes. Baseline CTCs, CCSC ratio, and $\mathrm{CD}^{+}{ }^{+}$ratio may predict prognosis in rmHNSCC.

Keywords: circulating tumor cells; cancer stem-like cells; PD-1; peripheral lymphocytes; head and neck cancer

\section{Introduction}

There are $>500,000$ new cases of head and neck squamous cell carcinoma (HNSCC) annually, with approximately 400,000 deaths worldwide [1,2]. Furthermore, the rates of new HNSCC cases and its incidence are 60,000 cases/year and 11.0/100,000 population in the USA, 63,500 cases/year and 11.2/100,000 population in Europe, and 7200 cases/year and 20.72/100,000 population in Taiwan [3,4]. Chemotherapy with or without targeted therapy remains a standard treatment for patients with initially unresectable, recurrent or metastatic HNSCC, although salvage surgery and re-irradiation may be possible for potentially resectable cases [5]. However, survival after disease progression or distant metastasis is relatively short, compared to other cancers [6], which contributes to the limited ability to switch chemotherapies. Moreover, the lack of useful and validated biomarkers to predict response is a major challenge during front-line palliative chemotherapy.

One promising biomarker is circulating tumor cells (CTCs), which can predict prognosis before starting therapy for various types of cancer [7-9]. These CTCs are shed from the primary tumor and can be detected in the patient's bloodstream, where they often express epithelial markers, such as epithelial cell adhesion molecule (EpCAM) [10] or cytokeratins [11], but typically do not express white and red blood cell markers, such as CD45 [12] and CD235a [13]. One exception is CTCs that are undergoing epithelial-mesenchymal transition processes [14]. Many investigators have found that CTCs can predict treatment response and have proposed monitoring CTC counts during anticancer therapy [15]. Moreover, a small subset of CTCs expresses stem cell markers, such as CD133 [16] or CD44 [17]. These cells can be referred to as circulating cancer stem-like cells (cCSCs), and are thought to be partially related to chemotherapy resistance [18-20]. Kantara et al. have reported several methods for identifying cCSCs using their expression of DCLK1, Lgr5, ANXA2, and PG, rather than CD44, and found that cCSCs were consistently related to chemotherapy resistance [21]. Nevertheless, the role of cCSCs in HNSCC remains unclear, especially regarding whether they are associated with prognosis or chemoresistance.

The relationship between host immune status and cancer cells is incompletely understood, and there has been a significant recent interest in the interaction between cancer and the host's immune status (e.g., $\mathrm{CD} 4^{+}$count, $\mathrm{CD} 8{ }^{+}$count, $\mathrm{CD} 4$ : $\mathrm{CD} 8$ ratio, and $\mathrm{CD}^{2} 6^{+}$fraction of peripheral lymphocytes) [22-27]. Programmed cell death protein 1 (PD-1) is a 55-kDa transmembrane protein with one extracellular IgV-like domain and a 97-amino acid cytoplasmic tail consisting of one immunotyrosine switch motif and one immunotyrosine inhibitory motif. PD-1 can be expressed on activated T cells, B cells, and myeloid cells. The function of PD-1 has been revealed to be an inhibitory role and a potential role in regulating tolerance and autoimmunity. PD-L1 is commonly upregulated on many different tumor types, where it inhibits anti-tumor $\mathrm{T}$ cell responses, and that PD- 1 is expressed on the majority of tumor-infiltrating lymphocytes That is an important rationale to block this pathway as novel cancer immunotherapies. One study has revealed that PD-1 expression on lymphocytes is significantly correlated with cancer prognosis. [22] For example, PD- 1 expression on peripheral CD4 $4^{+}$lymphocytes reflects impaired T-cell function and predicts poor clinical outcomes [23,24]. 
However, no studies have examined the associations of survival with PD-1 expression on peripheral lymphocytes (i.e., host immune status) plus the patient's CTC and cCSC status (i.e., markers for cancer aggressiveness). Therefore, this study aimed to evaluate whether CTCs, cCSCs and peripheral lymphocytes with/without PD-1 expression were associated with prognosis and therapy response among patients who were receiving palliative chemotherapy for initially unresectable, recurrent/metastatic HNSCC.

\section{Results}

\subsection{Patient Enrollment}

Between January 2015 and June 2016, 34 patients were enrolled after receiving a detailed explanation regarding the study's design, methods, and potential risks (Figure 1). The patients' basic characteristics are shown in Table 1, and all patients were followed until September 2017. The median follow-up time was 5.6 months ranging from 1.0-29.0 months. The median patient age was 50 years (range: $37-73$ years), and most patients were male (85.3\%). The most common primary sites were the oral cavity (55.9\%) and oropharynx (23.5\%). Most patients had an Eastern Cooperative Oncology Group performance status of $0-1(61.4 \%)$, and a smaller subgroup had a performance status of $\geq 2$ $(38.6 \%)$. The cases were classified as initially unresectable or recurrent $(n=4)$ or metastatic $(n=30)$, and no radiation was delivered during this study, although all patients received $\geq 2$ full cycles of palliative chemotherapy. The most common sites of distant metastasis were the lungs (53.3\%) and distant lymph nodes or soft tissue metastasis $(36.7 \%)$. The chemotherapy regimens mainly involved cisplatin-based regimens with or without cetuximab (82.4\%). Not all patients were evaluated for p16 expression, which was only detected in $8.8 \%(3 / 34)$ of the total population and $27.3 \%(3 / 11)$ in evaluated cases.

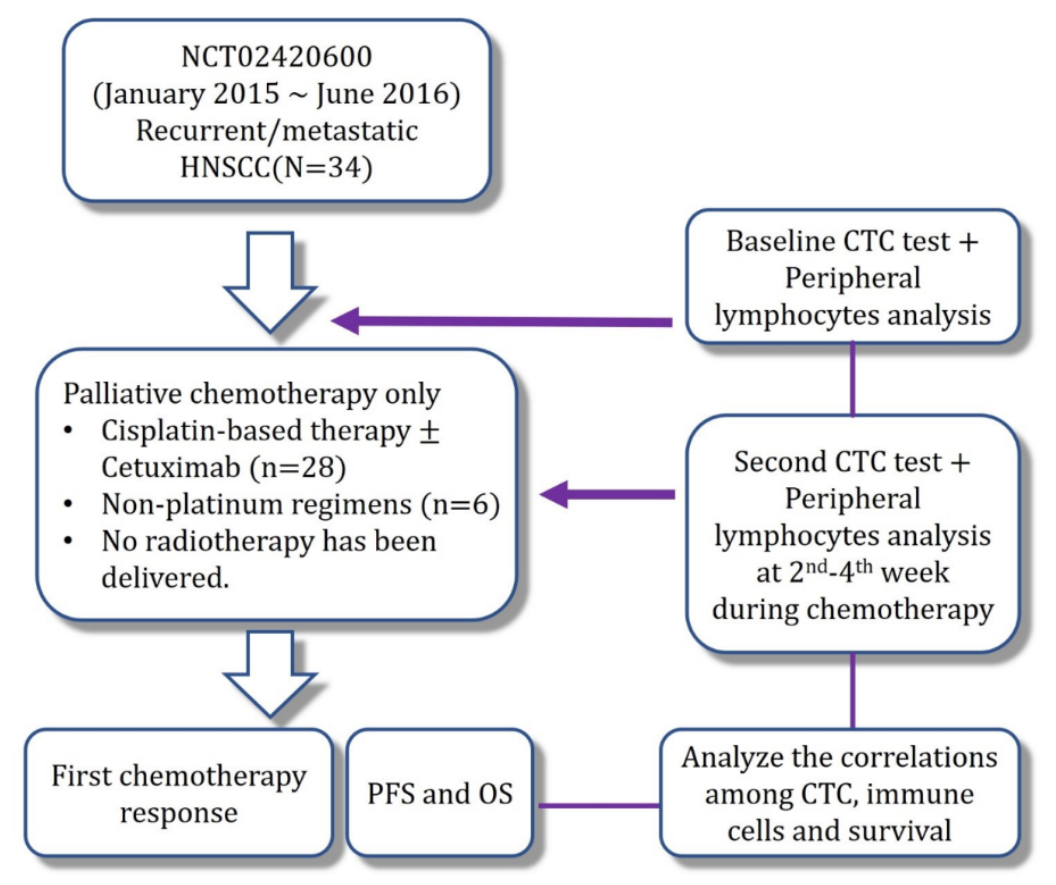

Figure 1. Study flow chart. 
Table 1. The patients' characteristics.

\begin{tabular}{|c|c|c|c|c|}
\hline Characteristic & $n$ & $\%$ & $\begin{array}{c}\text { Baseline CTCs (mean } \\
\pm \text { SD) }\end{array}$ & $p^{a}$ \\
\hline $\begin{array}{l}\text { Age (median, range), years } \\
\text { Sex }\end{array}$ & \multicolumn{2}{|c|}{$50(37-73)$} & $56.0 \pm 56.4$ & \\
\hline Male & 29 & $85.3 \%$ & $51.0 \pm 52.4$ & \\
\hline Female & 5 & $14.7 \%$ & $84.8 \pm 76.2$ & 0.252 \\
\hline \multicolumn{5}{|l|}{ Primary site } \\
\hline Oral cavity & 19 & $55.9 \%$ & $55.9 \pm 55.9$ & \\
\hline Oropharynx & 8 & $23.5 \%$ & $54.0 \pm 68.3$ & \\
\hline Hypopharynx & 5 & $14.7 \%$ & $68.1 \pm 56.3$ & \\
\hline Larynx & 1 & $2.9 \%$ & 40.0 & \\
\hline $\begin{array}{l}\text { Paranasal sinus } \\
\text { p16 status * }\end{array}$ & 1 & $2.9 \%$ & 29.8 & 0.974 \\
\hline Positive & 3 & $8.8 \%$ & $72.4 \pm 25.6$ & \\
\hline Negative & 8 & $23.5 \%$ & $22.8 \pm 13.2$ & \\
\hline Not examined & 23 & $67.6 \%$ & $52.0 \pm 10.8$ & 0.306 \\
\hline $\begin{array}{c}\text { Stage IVb/IVc (AJCC 7th edition) } \\
\text { Metastatic site }(n=30)\end{array}$ & \multicolumn{2}{|c|}{$4 / 30$} & $46.6 \pm 66.1 / 61.1 \pm 51.3$ & 0.482 \\
\hline Lung & 16 & $53.3 \%$ & $59.0 \pm 14.8$ & \\
\hline $\begin{array}{c}\text { Distant lymph node or soft tissue } \\
\text { metastasis }\end{array}$ & 11 & $36.7 \%$ & $37.5 \pm 11.3$ & \\
\hline Bone & 11 & $36.7 \%$ & $33.6 \pm 10.1$ & \\
\hline Skin carcinomatosis & 9 & $30.0 \%$ & $68.6 \pm 22.9$ & \\
\hline Liver & 2 & $6.70 \%$ & $30.9 \pm 21.9$ & 0.610 \\
\hline First-line palliative chemotherapy & 34 & $100.0 \%$ & & \\
\hline Cisplatin-based therapy \pm cetuximab & 28 & $82.4 \%$ & $63.1 \pm 59.5$ & \\
\hline $\begin{array}{l}\text { Non-platinum regimens } \\
\text { (cisplatin-refractory) }\end{array}$ & 6 & $17.6 \%$ & $22.8 \pm 17.1$ & 0.114 \\
\hline
\end{tabular}

* p16 immunohistochemistry staining for p16 expression was examined in 11 patients, including eight oropharyngeal, three hypopharyngeal, and one laryngeal cancer patients. AJCC = American Joint Committee on Cancer. $\mathrm{CTC}=$ circulating tumor cells. ${ }^{a}$. The $\mathrm{P}$ values were calculated by independent Mann-Whitney $\mathrm{U}$ tests.

\subsection{Multivariate Analysis of Survival Outcomes}

The CTC and CCSC analyses were performed using both cell line controls and samples from patients with HNSCC (Figures 2 and 3). The lymphocytes' PD-1 expression status is shown in Figure S1, as well as for the white blood cells (WBC) controls that underwent polyhydroxyalkanoate induction. Multivariate analyses revealed that disease progression was independently predicted by the baseline CTC number (hazard ratio [HR]: 1.01,95\% confidence interval [CI]: 1.005-1.022) and the CCSC ratio (HR: 10.92, 95\% CI: 2.295-51.957) (Table 2). The multivariate analyses revealed that overall survival (OS) was independently predicted by the baseline CTC number (HR: 1.01, 95\% CI: 1.003-1.017), the CCSC ratio (HR: 29.90, 95\% CI: 5.420-164.992), and the baseline CD8 ${ }^{+}$proportion (HR: $0.24,95 \%$ CI: 0.091-0.640). The Kaplan-Meier survival curves revealed that a high baseline CD8 ${ }^{+}$proportion $(\geq 17 \%)$ predicted prolonged PFS and OS (Figure 4a,b), while a higher CD4: CD8 ratio predicted shorter Progression-free survival (PFS) and OS (Figure 4c,d). The details of CTC, cCSC, CD4, CD8, and CD4:8 ratios before and during chemotherapy were shown in Table S1. Their correlations among basic characteristics were listed in Table S2. 
Table 2. Univariate and multivariate analyses of survival.

\begin{tabular}{|c|c|c|c|c|c|c|c|c|}
\hline \multirow{3}{*}{ Factor } & \multicolumn{4}{|c|}{ PFS } & \multicolumn{4}{|c|}{ OS } \\
\hline & \multicolumn{2}{|l|}{ Univariate } & \multicolumn{2}{|l|}{ Multivariate } & \multicolumn{2}{|l|}{ Univariate } & \multicolumn{2}{|l|}{ Multivariate } \\
\hline & HR (95\% CI) & $p$-Value & HR $(95 \%$ CI) & $p$-Value & HR $(95 \%$ CI) & $p$-Value & HR $(95 \%$ CI) & $p$-Value \\
\hline Age & $1.001(0.962-1.041)$ & 0.968 & & & $1.005(0.965-1.047)$ & 0.805 & & \\
\hline Primary site & $1.059(0.799-1.404)$ & 0.688 & & & $0.986(0.759-1.280)$ & 0.913 & & \\
\hline ECOG & $1.341(0.856-2.100)$ & 0.200 & & & $1.571(1.062-2.326)$ & 0.024 & & \\
\hline CTC & $1.008(1.000-1.015)$ & 0.036 & $1.013(1.005-1.022)$ & 0.002 & $1.005(0.999-1.010)$ & 0.12 & $1.010(1.003-1.017)$ & 0.004 \\
\hline cCSC ratio & $4.367(1.206-15.808)$ & 0.025 & $10.920(2.295-51.957)$ & 0.003 & $9.788(2.300-41.661)$ & 0.002 & $29.903(5.420-164.992)$ & $<0.0001$ \\
\hline PD1 on $\mathrm{CD}^{+}{ }^{+}$ & $1.001(0.985-1.017)$ & 0.897 & & & $0.995(0.977-1.013)$ & 0.58 & & \\
\hline PD1 on CD56 ${ }^{+}$ & $1.013(0.991-1.035)$ & 0.235 & & & $1.001(0.982-1.020)$ & 0.918 & & \\
\hline PD1 on $\mathrm{CD}^{+}$ & $0.997(0.971-1.024)$ & 0.828 & & & $1.002(0.979-1.025)$ & 0.872 & & \\
\hline $\mathrm{CD}^{+}$ & $1.022(0.991-1.054)$ & 0.174 & & & $1.003(0.975-1.031)$ & 0.837 & & \\
\hline $\mathrm{CD}^{2} 6^{+}$ & $0.961(0.922-1.002)$ & 0.060 & & & $0.965(0.922-1.010)$ & 0.123 & & \\
\hline $\mathrm{CD}^{+}$proportion $\geq 17 \%$ vs. $<17 \%$ & $0.319(0.124-0.821)$ & 0.018 & & & $0.236(0.094-0.595)$ & 0.002 & $0.242(0.091-0.640)$ & 0.004 \\
\hline CD4:CD8 ratio $\geq 1.2$ vs. $<1.2$ & $2.538(1.230-5.237)$ & 0.012 & $2.120(0.959-4.688)$ & 0.064 & $2.403(1.130-5.109)$ & 0.023 & & \\
\hline
\end{tabular}

Abbreviations: ECOG PS, Eastern Cooperative Oncology Group performance status; HR, hazard ratio; PFS, progression-free survival; OS, overall survival; CTC, circulating tumor cells; cCSC,

circulating cancer stem-like cells; cCSC ratio, $\mathrm{CD} 133^{+} \mathrm{EpCAM}^{+} \mathrm{Hoechst}^{+} \mathrm{CD} 45^{-}$cells divided by EpCAM ${ }^{+} \mathrm{Hoechst}^{+} \mathrm{CD} 45^{-}$cells. 

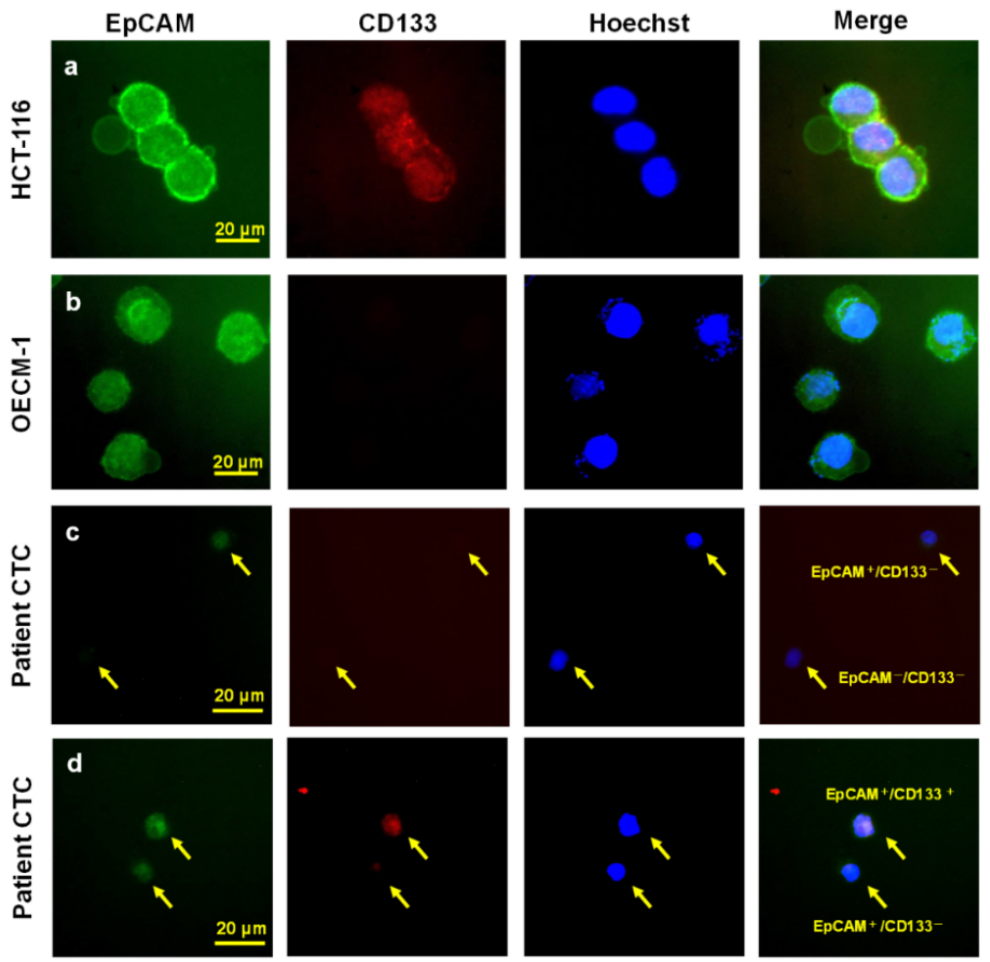

Figure 2. Detecting circulating tumor cells (CTCs) and circulating cancer stem-like cells (cCSCs) using immunofluorescence (Patient No.16 and Patient No.21). (a) HCT116 as the demonstrated cell line for $\mathrm{EpCAM}^{+} / \mathrm{CD}_{133^{+}}$cells. (b) The OECM-1 as the demonstrated cell line for $\mathrm{EpCAM}^{+} / \mathrm{CD} 133^{-}$ cells. (c) In Patient No. 16, the image showed the $\mathrm{EpCAM}^{+} / \mathrm{CD}_{133^{-}}$and $\mathrm{EpCAM}^{-} / \mathrm{CD} 133^{-} \mathrm{CTC}$. (d) In Patient No. 21, the image showed the EpCAM ${ }^{+} / \mathrm{CD}_{133^{+}}$and $\mathrm{EpCAM}^{+} / \mathrm{CD}_{133^{-}} \mathrm{CTC}$.
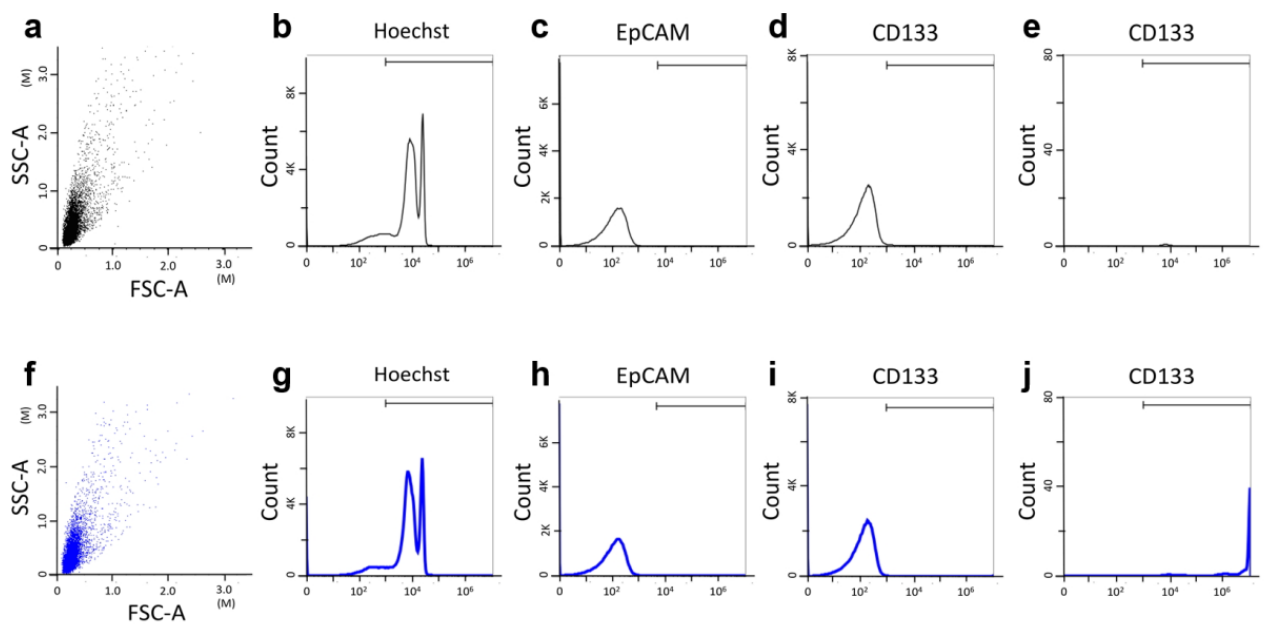

Figure 3. Detecting circulating tumor cells (CTCs) and circulating cancer stem-like cells (cCSCs) using flow cytometry. Panel (a-e) shows the isotype control (Hoechst and mouse IgG isotypes for EpCAM and CD133) for CTC and CCSC analysis. Panel (f-j) demonstrates real cancer patients' CTC and cCSC by staining with Hoechst, EpCAM, and CD133 antibodies after red and white blood cells depletion protocol. The gating algorithms are SSC and FSC for whole cell distribution in panel $(\mathbf{a}, \mathbf{f})$. Then we gated cells with positive Hoechst expression nucleated cells population in panel $(\mathbf{b}, \mathbf{g})$. Based on positive Hoechst situation, EpCAM positive cells were selected and defined as CTCs in panel (c,h). Panel (d,i) shows the gating rationale for $\mathrm{CD}_{133^{+}}$cells based on positive Hoechst situation. For the definition of cCSCs, CD133-positive cells were gated based on $\mathrm{EpCAM}^{+} \mathrm{Hoechst}^{+}$cells as illustrated in panel (e,j). The cell count of $\mathrm{CD}_{133^{+}} \mathrm{EpCAM}^{+} \mathrm{Hoechst}^{+}$after negative selection strategy was 17 cells (e) and 220 cells (j). 

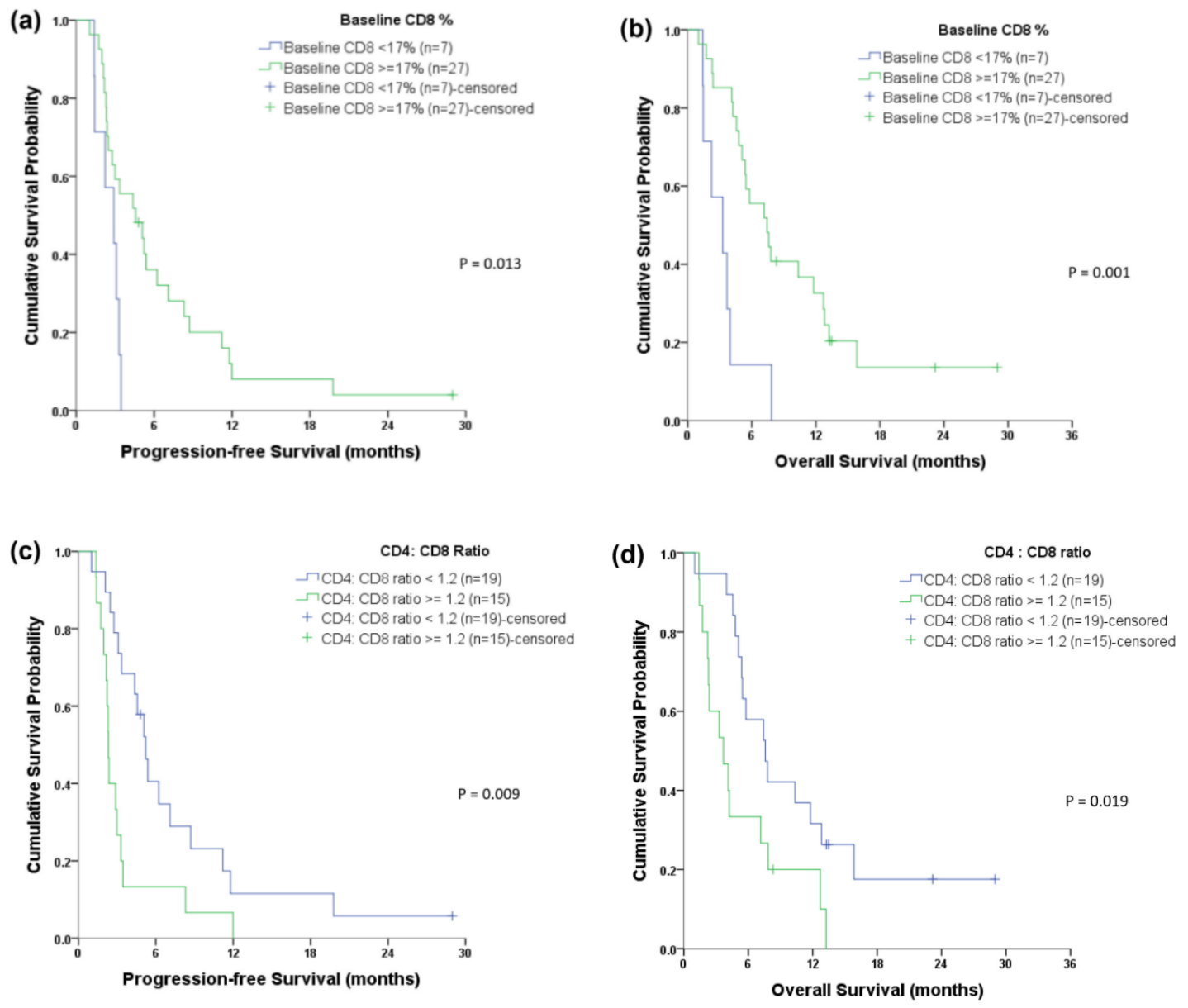

Figure 4. Kaplan-Meier curves for the survival analyses. A higher baseline CD8 ${ }^{+}$proportion was associated with better (a) progression-free survival (PFS) and (b) overall survival (OS). A lower baseline CD4: CD8 ratio was associated with better (c) PFS and (d) OS.

\subsection{The cCSC Ratio May Contribute to Chemoresistance}

We had hypothesized that a high CCSC ratio might predict a poor response to chemotherapy, based on the chemoresistance of CCSCs. Figure 5 and Table 2 show that a higher baseline CCSC ratio predicted disease progression within the first three months of chemotherapy ( $p=0.003$ based on the Mann-Whitney U test).

\section{Cancer Progression within 3 months}

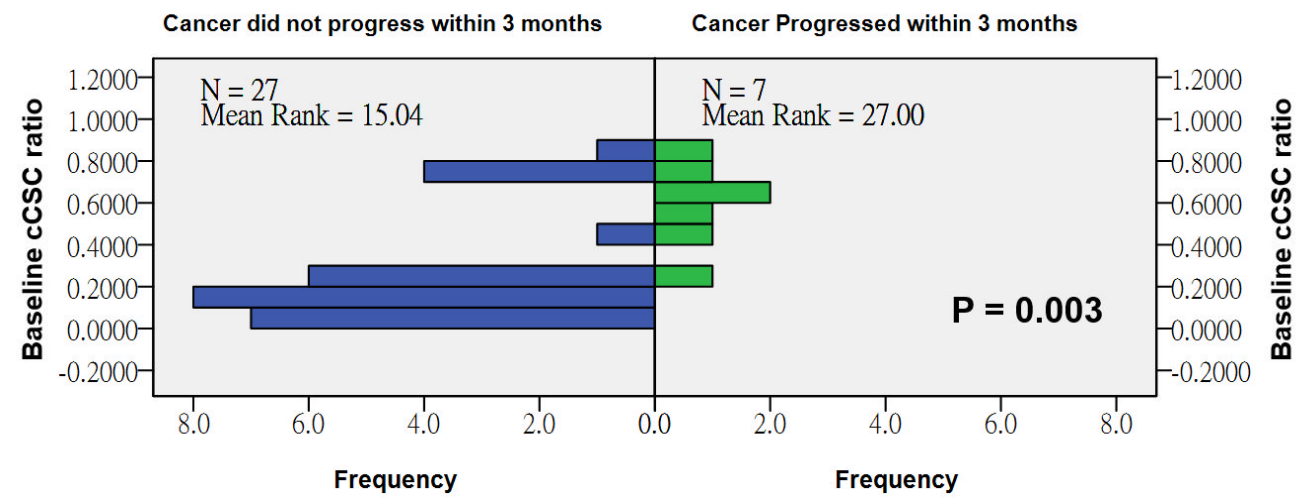

Figure 5. The presence of circulating cancer stem-like cells (cCSCs) could predict rapid disease progression within 3 months ( $p=0.003$ based on the Mann-Whitney $U$ test). 


\subsection{PD-1 Expression on $C D 4^{+}, C D 8^{+}$, and $C D 56^{+} T$ Lymphocytes}

There were no significant associations between the survival outcomes and PD-1 expression on $\mathrm{CD}^{+}, \mathrm{CD}^{+}$, or $\mathrm{CD} 56^{+}$T lymphocytes.

\section{Discussion}

This prospective study evaluated 34 patients with initially unresectable, recurrent/metastatic HNSCC to examine whether chemotherapy response could be predicted using CTC, CCSC, and peripheral lymphocyte expression of PD-1. The results indicate that CTCs and CCSCs were independent predictors of cancer progression and OS and that patients with a high baseline $\mathrm{CD} 8^{+}$proportion had longer OS, while patients with a lower CD4: CD8 ratio had longer PFS. However, PD-1 expression on peripheral lymphocytes was not a significant predictor of the survival outcomes. To the best of our knowledge, this is the first study to examine CTC/cCSC and immune status using a single blood sample from patients with HNSCC.

Many studies have addressed the role of CTCs in HNSCC [25-30], including our previous study [8]. The results of the present study support the findings of the previous studies and indicate that CTC independently predicts prognosis in cases of HNSCC. In a previous stud [8], we cannot identify the prognostic role from CTC alone. One of the plausible reasons might be the improved stability and internal controls for the platform, which makes the enumerated CTC number more clinically and biologically significance by exclusion false positive signal. In addition, several studies have examined the role of cCSCs in cancer cases, which were examined using RT-PCR [31,32], counting with a gradient protocol $[17,33]$, or flow cytometry $[34,35]$. Those results indicate that CCSCs are linked to a poor prognosis in cases of colorectal cancer [31,36], gastric cancer [17], prostate cancer [37], lung cancer [34,38], and hepatocellular carcinoma [32]. However, to the best of our knowledge, this is the first report to indicate that CCSCs reflect a positive prognosis in cases of HNSCC. In contrast, Park et al. [39] used a similar methodology and reported that the presence of $\mathrm{CD} 133^{+} \mathrm{EpCAM}^{+}$cells was associated with a poor prognosis in 10 cases of colorectal cancer. It is possible that the small sample sizes and different cancer types may explain the discrepancy between our findings and those of Park et al. Furthermore, studies have used different definitions of CCSCs, which we defined as expressing both CD133 and EpCAM after CD45 depletion. Thus, the different definitions might also explain the conflicting findings regarding the roles of cCSCs. For example, Toyoshima et al. defined cCSCs as CD44 ${ }^{+}$cells and reported that they had tumorigenicity [17], while Rentala et al. [40] defined cCSCs as cells that were CD133 ${ }^{+} \mathrm{CD} 44^{+}$. The most commonly used marker for identifying cCSCs is likely CD133 [31], and we included this marker to improve the ability to compare and validate our findings.

The present study revealed that high baseline peripheral CD8 ${ }^{+}$cells and low CD4: CD8 ratio were associated with a good prognosis. However, there is debate regarding the usefulness of peripheral lymphocytes versus tumor-infiltrating lymphocytes (TILs), as some investigators believe that TILs reflect the true tumor microenvironment and are correlated with prognosis and treatment response, despite the difficulty of repeated biopsy [41,42]. However, other reports have indicated that CD8 ${ }^{+}$ TILs have no prognostic value in cases of HNSCC [39]. Therefore, we selected peripheral lymphocytes rather than TILs for the present study, as they are easier to monitor and may be useful as a follow-up marker (we hope to publish follow-up data in a later report).

Our results support the positive effects of higher baseline peripheral CD8 ${ }^{+} \mathrm{T}$-cell proportions $[40,43]$ and lower CD4:8 ratios [44,45] in cancer cases, especially among patients with HNSCC [46]. Nevertheless, our results are different from those reported by Dewyer et al., who found that pre-induction chemotherapy $\mathrm{CD} 4^{+} \mathrm{T}$-cells but not $\mathrm{CD} 8^{+} \mathrm{T}$-cells were correlated with a good prognosis and treatment response [47]. These differences may be related to the fact that we mainly enrolled patients with oral cavity cancer, while Dewyer et al. enrolled patients with laryngeal cancer, which suggests that the primary site may influence the prognostic markers. In addition, we examined the 
relative proportion of $\mathrm{CD}^{+}$cells, while Dewyer et al. performed absolute counting of lymphocytes. Thus, the different measurement units may explain the different findings.

The expression of PD-1 on lymphocytes has been widely discussed during recent years, and Waki et al. have reported that PD- 1 expression on $\mathrm{CD}^{+}$and $\mathrm{CD}^{+} \mathrm{T}$ lymphocytes was correlated with OS among patients with lung cancer who received personalized peptide vaccination [22]. However, our study failed to detect significant relationships between the survival outcomes and the expression of PD- 1 on $\mathrm{CD}_{4}^{+}, \mathrm{CD} 8^{+}$, or $\mathrm{CD} 56^{+} \mathrm{T}$ lymphocytes. It is possible that our negative findings are related to the small sample size and/or an insufficient cut-off for PD-1 positivity. For example, it may be more appropriate to use the difference between PD-1 staining and polyhydroxyalkanoate induction of control cells (Figure S1), and further adjustment of PD-1 staining or methodology standardization should be considered in future studies. However, Lyford-Pike et al. found that PD-1 expression on $\mathrm{CD}^{+} \mathrm{T}$-cells and $\mathrm{CD} 8^{+} \mathrm{T}$-cells was higher in tonsil tissue, compared to the peripheral blood, of patients with HNSCC [48], which indicates that PD-1 expression on peripheral blood lymphocytes may not be clinically significant, and our results support that possibility. Thus, PD-1 expression may only have prognostic value when it is observed on TILs.

The present study has several limitations. First, the sample size was small and a larger prospective study is needed to validate our findings. Second, despite the benefits of dynamic follow-up using peripheral lymphocytes, there is debate regarding whether they reflect the whole body's immune status, as their properties are easily disturbed. Third, although we used a clear and strict definition for cCSCs, we did not isolate these cells and confirm that they possessed in-vivo tumorigenicity, invasion, or self-renewal, which is why we referred to them as "stem-like" cells.

\section{Materials and Methods}

\subsection{Study Design}

This prospective observational study examined baseline CTCs, cCSCs, and PD-1 expression on peripheral lymphocytes, as well as progression-free survival (PFS) and overall survival (OS) among patients with initially unresectable, recurrent/metastatic HNSCC. The analyses were performed when more than half of the events had occurred, and the ratio of CCSC to CTC was selected to evaluate its ability to predict cancer progression and cancer-related death. Two CTC samplings were performed, with the first being performed at baseline (seven days before the first dose of chemotherapy) and the second being performed at 14-28 days after the first dose of chemotherapy. Study results were reported according to the Reporting Recommendations for Tumour Marker Prognostic Studies (REMARK) guidelines.

\subsection{Patient Enrollment}

Patients were enrolled at the Chang Gung Memorial Hospital (Linkou, Taiwan), and the observational protocol was approved by the institutional review board of Chang Gung Memorial Hospital (103-5322B). All patients provided written informed consent before being enrolled. Patients were considered eligible if they had: (1) histologically or cytopathologically confirmed stage IVb HNSCC (initially unresectable or recurrent) or stage IVc HNSCC (metastatic), based on the 7th edition of the American Joint Committee on Cancer criteria, (2) were $\geq 20$ years old, (3) provided informed consent, and (4) had adequate liver and renal functions with a sufficient white blood cell count (WBC) to tolerate the anticancer therapies (especially chemotherapy). Patients were excluded if they had synchronous cancer or previous cancers within the last five years.

Blood samples were drawn within seven days before the first dose of chemotherapy. Disease staging, disease management, and treatment response evaluations followed the standard treatment protocols and institutional guidelines and were based on the findings from computed tomography, pan-endoscopy, magnetic resonance imaging, and positron emission tomography. Chemotherapy was scheduled and delivered by medical oncologists who were part of the head and neck tumor board at 
Chang Gung Memorial Hospital. Based on the Response Evaluation Criteria in Solid Tumors guidelines (version 1.0), treatment response was classified as complete remission, partial response, stable disease, or progressive disease. Disease-specific PFS was calculated from the date of the first CTC sampling to the first instance of cancer-specific disease progression or death, and OS was calculated from the date of the first CTC sampling to the date of death from any cause.

\subsection{Chemotherapy Regimens}

Palliative chemotherapy regimens were selected after full discussions with the patient's family. The regimens mainly contained cetuximab $\left(400 \mathrm{mg} / \mathrm{m}^{2}\right.$ and then $250 \mathrm{mg} / \mathrm{m}^{2}$ weekly for three consecutive months; Merck, Darmstadt, Germany), cisplatin (50-75 mg/ $\mathrm{m}^{2}$ biweekly to triweekly), and 5-fluorouracil (700-1000 mg/m²/day as a continuous infusion during days 1-4 every 28 days). Other treatments option involved methotrexate $\left(40 \mathrm{mg} / \mathrm{m}^{2}\right.$ or a fixed weekly dose of $\left.50 \mathrm{mg}\right)$, bleomycin (15 mg weekly), and oral tegafur-uracil (300 mg/m²/day; TTY Biopharm Co. Ltd., Taipei, Taiwan) according to institutional guideline at Chang Gung Memorial Hospital.

\subsection{Identifying CTCs and cCSCs}

The CTCs were identified using negative selection and positive detection strategies, which were validated in our previous studies [49]. The first step involves a negative selection protocol that depletes red blood cells using lysis and leukocytes using a CD45 depletion kit (STEMCELL Technologies Inc., Vancouver, BC, Canada). The second step involves using flow cytometry to quantitatively identify CTCs $\left(\mathrm{EpCAM}^{+}\right.$Hochest $\left.^{+} \mathrm{CD} 45^{-}\right)$and cCSCs $\left(\mathrm{CD} 133^{+} \mathrm{EpCAM}^{+}\right.$Hochest $\left.^{+} \mathrm{CD} 45^{-}\right)$. The ratio of cCSCs to CTCs was calculated and reported as a percentage.

The CTC tests were performed using $4 \mathrm{~mL}$ of peripheral blood after discarding the first $4 \mathrm{~mL}$ of blood to avoid epithelial contamination. Red blood cell lysis was performed within $72 \mathrm{~h}$, and further negative selection was performed using the EasySep CD45 Depletion Cocktail $(25 \mu \mathrm{L} / \mathrm{mL}$; STEMCELL Technologies Inc., Vancouver, BC, Canada) and EasySep Magnetic Nanoparticles $(50 \mu \mathrm{L} / \mathrm{mL}$; STEMCELL). The immunomagnetically enriched samples were subsequently spiked with OECM1 cells, labelled using an Alexa Fluor ${ }^{\circledR}$ 488-conjugated monoclonal antibody to EpCAM (1:400; Cell Signaling Technology Inc., Danvers, MA, USA), and stained with Hoechst 33342 (1:500 in washing solution; Thermo Scientific, Waltham, MA, USA) for the nuclear staining. An isotype control antibody was used as an internal control, as well as peripheral blood samples from healthy individuals (4 mL) that were and were not spiked with 1000 OECM1 cells, which had been purchased from Taiwan's Food Industry Research and Development Institute (Hsinchu, Taiwan). Performance recovery was defined as the proportion of OECM1 cells detected using flow cytometry (BD FACSCalibur; BD Biosciences, San Jose, CA, USA) to the number of spiked OECM1 cells, and a stable coefficient of variation (CV) value has been calculated in a previous report $[49,50]$. To be brief, the platform can have a recovery rate of $44.6 \pm 9.1 \%$ and a \% coefficient of variation $(C V)$ of $20.4 \%$. The previous platform reported in 2015 would detect $13.1 \pm 0.9$ cells/mL in healthy individuals $(n=20)$ [49], which was confusing and might be background signal (false positive). In this revised platform, isotype control was used for each sample, which resulted in a range of $0.0-3.0$ cells $/ \mathrm{mL}$ in healthy individuals in this study cohort $(n=20)$. CTCs were defined as cells that were positive for both EpCAM and Draq5. Immunohistochemistry was performed to detect p16 using a prediluted mouse monoclonal antibody (CINtec p16INK4a [clone E6H4]; Roche Laboratories Inc., Westborough, MA, USA) [51] and a Dako Autostainer (Dako North America Inc., Carpinteria, CA, USA), according to the manufacturer's protocol.

\subsection{PD-1 Staining and Controls}

Peripheral blood mononuclear cells were isolated from $4 \mathrm{~mL}$ of healthy volunteers' blood using a Ficoll-Hypaque density gradient. The cells were then cultured in RPMI medium containing $10 \%$ fetal bovine serum (FBS) for $72 \mathrm{~h}$ with or without stimulation using $2 \%$ phytohemagglutinin (M form; 
Thermo Fisher GIBCO, Waltham, MA, USA.) (Figure S1). The harvested cells were subsequently used in the immunoassays as controls that were positive and negative for PD-1 expression.

\subsection{Immune Activity Assay}

After red blood cell lysis, WBCs were collected from $2 \mathrm{~mL}$ of the patients' blood and subjected to flow cytometry after surface staining using a CD4-FITC antibody (eBiosciences; San Diego, CA, USA), a CD8a-PE-Cy7 antibody (eBiosciences), and a PD-1-PE antibody (BD Pharmingen, San Jose, CA, USA). A total of $2 \times 10^{5} \mathrm{WBC}$ were resuspended in $100 \mu \mathrm{L}$ of RPMI medium with $10 \% \mathrm{FBS}, 0.25 \mu \mathrm{g}$ of the CD4-FITC antibody, $0.06 \mu \mathrm{g}$ of the CD8a-PE-Cy7 antibody, and $20 \mu \mathrm{L}$ of the PD-1-PE antibody. The corresponding isotype control antibodies were used under the same conditions. After staining for $1 \mathrm{~h}$, the cells were washed using $2 \mathrm{~mL}$ of phosphate-buffered saline solution containing $10 \% \mathrm{FBS}$ and $1 \mathrm{mM}$ EDTA. The fluorescence measurements were performed using a CytoFLEX Flow cytometer (Beckman Coulter, Brea, CA, USA). The gating strategies were (1) $2 \times 10^{4}$ events for $\mathrm{CD} 4^{+} / \mathrm{CD} 8^{+}$-gated cells, (2) positive and negative signals for PD-1 expression were based on the $\mathrm{CD} 4^{+}$or $\mathrm{CD} 8^{+}$cursors to yield positive signals after subtracting the signal from the PE-conjugated isotype control, and (3) the percentages of $\mathrm{CD} 4^{+}$and $\mathrm{CD} 8^{+}$cells were calculated, as well as the proportions of $\mathrm{CD} 4^{+}$and $\mathrm{CD} 8^{+}$ cells that were positive for PD-1.

\subsection{Statistical Analysis}

The patients' demographic data were reported as number (percentage) for categorical variables, and median (range) for continuous variables. Univariate and multivariate analysis were used, all factors used in the univariate analysis were examined in multivariate analysis but only those factors with statistical significance were displayed. A multivariate Cox's proportional hazard model using the forward stepwise approach was used to examine the variables' associations with OS and PFS. A risk model was also developed from the multivariate analysis. Kaplan-Meier curves and the log-rank test were used to examine any differences in the OS and PFS outcomes and determine the cutoffs, including the ratio of $\mathrm{CD} 8^{+}$and $\mathrm{CD} 4$ : CD8. All analyses were performed using SPSS software (version 18; SPSS Inc., Chicago, IL, USA), and $p$-values of $<0.05$ were considered statistically significant.

\section{Conclusions}

This prospective study revealed that baseline CTCs and the cCSC ratio (i.e., cancer status), as well as the $\mathrm{CD} 8{ }^{+}$proportion and the $\mathrm{CD} 4$ : $\mathrm{CD} 8$ ratio (i.e., host immune status), were significantly associated with the prognosis of HNSCC. Furthermore, the baseline cCSC ratio could predict chemotherapy response during the first three months, which suggests that these cells are involved in chemoresistance.

Supplementary Materials: The following are available online at http://www.mdpi.com/2072-6694/11/4/540/s1, Figure S1: Phytohemagglutinin induction for PD-1 expression as controls and the PD-1 expression on CD4 ${ }^{+}$and $\mathrm{CD} 8^{+}$cells analysis using flow cytometry. Table S1: Circulating tumor cells, circulating cancer stem-like cells and peripheral lymphocytes with chemotherapy responses, Table S2. Correlations among basic characteristics and baseline cCSC, CD8\% and CD4:8 ratio.

Author Contributions: Conceptualization, P.-H.C., M.-H.W., S.-Y.L. and J.C.-H.H.; Data curation, S.-Y.L., H.-M.W. and C.-T.L.; Formal analysis, M.-H.W. and S.-Y.L.; Funding acquisition, P.-H.C., H.-M.W., C.-T.L. and J.C.-H.H.; Methodology, S.-H.N.; Software, W.-K.H. and H.-C.L.; Supervision, C.-T.L., T.-C.Y., S.-H.N., J.-S.C. and Y.-C.L.; Validation, H.-M.W., W.-K.H., T.-C.Y. and H.-C.L.; Writing-original draft, J.C.-H.H.; Writing-review \& editing, P.-H.C. and M.-H.W., P.-H.C., M.-H.W. and S.-Y.L. contributed equally to this work. All authors agree for this authorship.

Funding: This study was fully or partially supported by 107-TDU-B-212-114023(PMRPG3H0071), CMRPG3G0591-3, CORPG3F0731, CMRPG3E1631-33, MOST-107-2628-B-182A-001- to C.-H.H., CMRPG2G0681-3, CMRPG2D0171 to P.-H.C., CMRPG3G1131-1133, CMRPG3H0871-73, MOST-107-2314-B-182-053, MOST-104-2314-B-182-031-MY3 to H.-M.W., and CMRPG3D1063, CMRPG3D1073, MOST104-2314-B-182A-073-MY3 to C.-T.L.

Acknowledgments: The authors thank all members of the Cancer Centre, Chang Gung Memorial Hospital, for their invaluable help. We also gratefully acknowledged the anonymous reviewer's invaluable advice.

Conflicts of Interest: The authors have no conflict of interest and no competing financial interests to declare. 


\section{References}

1. Shield, K.D.; Ferlay, J.; Jemal, A.; Sankaranarayanan, R.; Chaturvedi, A.K.; Bray, F.; Soerjomataram, I. The global incidence of lip, oral cavity, and pharyngeal cancers by subsite in 2012. CA Cancer J. Clin. 2017, 67, 51-64. [CrossRef]

2. Global Burden of Disease Cancer Collaboration; Fitzmaurice, C.; Allen, C.; Barber, R.M.; Barregard, L.; Bhutta, Z.A.; Brenner, H.; Dicker, D.J.; Chimed-Orchir, O.; Dandona, R.; et al. Global, Regional, and National Cancer Incidence, Mortality, Years of Life Lost, Years Lived with Disability, and Disability-Adjusted Life-years for 32 Cancer Groups, 1990 to 2015: A Systematic Analysis for the Global Burden of Disease Study. JAMA Oncol. 2017, 3, 524-548. [CrossRef]

3. Gatta, G.; Botta, L.; Sanchez, M.J.; Anderson, L.A.; Pierannunzio, D.; Licitra, L.; Group, E.W. Prognoses and improvement for head and neck cancers diagnosed in Europe in early 2000s: The EUROCARE-5 population-based study. Eur. J. Cancer 2015, 51, 2130-2143. [CrossRef] [PubMed]

4. Department of Health, The Executive Yuan, R.O.C. December 2006: Cancer Registry: Annual Report in Taiwan Area; The Executive Yuan, R.O.C.: Taipei, Taiwan, 2006. (In Chinese)

5. Argiris, A.; Karamouzis, M.V.; Raben, D.; Ferris, R.L. Head and neck cancer. Lancet 2008, 371, $1695-1709$. [CrossRef]

6. Medow, M.A.; Weed, H.G.; Schuller, D.E. Simple predictors of survival in head and neck squamous cell carcinoma. Arch. Otolaryngol. Head Neck Surg. 2002, 128, 1282-1286. [CrossRef] [PubMed]

7. Hou, J.M.; Krebs, M.G.; Lancashire, L.; Sloane, R.; Backen, A.; Swain, R.K.; Priest, L.J.; Greystoke, A.; Zhou, C.; Morris, K.; et al. Clinical significance and molecular characteristics of circulating tumor cells and circulating tumor microemboli in patients with small-cell lung cancer. J. Clin. Oncol. 2012, 30, 525-532. [CrossRef]

8. Hsieh, J.C.; Lin, H.C.; Huang, C.Y.; Hsu, H.L.; Wu, T.M.; Lee, C.L.; Chen, M.C.; Wang, H.M.; Tseng, C.P. Prognostic value of circulating tumor cells with podoplanin expression in patients with locally advanced or metastatic head and neck squamous cell carcinoma. Head Neck 2015, 37, 1448-1455. [CrossRef]

9. Scher, H.I.; Jia, X.Y.; de Bono, J.S.; Fleisher, M.; Pienta, K.J.; Raghavan, D.; Heller, G. Circulating tumour cells as prognostic markers in progressive, castration-resistant prostate cancer: A reanalysis of IMMC38 trial data. Lancet Oncol. 2009, 10, 233-239. [CrossRef]

10. De Wit, S.; van Dalum, G.; Lenferink, A.T.; Tibbe, A.G.; Hiltermann, T.J.; Groen, H.J.; van Rijn, C.J.; Terstappen, L.W. The detection of $\operatorname{EpCAM}(+)$ and $\operatorname{EpCAM}(-)$ circulating tumor cells. Sci. Rep. 2015, 5, 12270. [CrossRef] [PubMed]

11. Kawada, T.; Takahashi, H.; Sakakura, K.; Ida, S.; Mito, I.; Toyoda, M.; Chikamatsu, K. Circulating tumor cells in patients with head and neck squamous cell carcinoma: Feasibility of detection and quantitation. Head Neck 2017, 39, 2180-2186. [CrossRef]

12. Jiang, J.; Zhao, H.; Shu, W.; Tian, J.; Huang, Y.; Song, Y.; Wang, R.; Li, E.; Slamon, D.; Hou, D.; et al. An integrated microfluidic device for rapid and high-sensitivity analysis of circulating tumor cells. Sci. Rep. 2017, 7, 42612. [CrossRef] [PubMed]

13. Lapin, M.; Tjensvoll, K.; Oltedal, S.; Buhl, T.; Gilje, B.; Smaaland, R.; Nordgard, O. MINDEC-An Enhanced Negative Depletion Strategy for Circulating Tumour Cell Enrichment. Sci. Rep. 2016, 6, 28929. [CrossRef] [PubMed]

14. Zeisberg, M.; Neilson, E.G. Biomarkers for epithelial-mesenchymal transitions. J. Clin. Investig. 2009, 119, 1429-1437. [CrossRef] [PubMed]

15. Yang, B.; Qin, A.; Zhang, K.; Ren, H.; Liu, S.; Liu, X.; Pan, X.; Yu, G. Circulating Tumor Cells Predict Prognosis Following Tyrosine Kinase Inhibitor Treatment in EGFR-Mutant Non-Small Cell Lung Cancer Patients. Oncol. Res. 2017, 25, 1601-1606. [CrossRef] [PubMed]

16. Nadal, R.; Ortega, F.G.; Salido, M.; Lorente, J.A.; Rodriguez-Rivera, M.; Delgado-Rodriguez, M.; Macia, M.; Fernandez, A.; Corominas, J.M.; Garcia-Puche, J.L.; et al. CD133 expression in circulating tumor cells from breast cancer patients: Potential role in resistance to chemotherapy. Int. J. Cancer 2013, 133, 2398-2407. [CrossRef] [PubMed]

17. Toyoshima, K.; Hayashi, A.; Kashiwagi, M.; Hayashi, N.; Iwatsuki, M.; Ishimoto, T.; Baba, Y.; Baba, H.; Ohta, Y. Analysis of circulating tumor cells derived from advanced gastric cancer. Int. J. Cancer 2015, 137, 991-998. [CrossRef] [PubMed] 
18. Yang, Z.F.; Ngai, P.; Ho, D.W.; Yu, W.C.; Ng, M.N.; Lau, C.K.; Li, M.L.; Tam, K.H.; Lam, C.T.; Poon, R.T.; et al. Identification of local and circulating cancer stem cells in human liver cancer. Hepatology 2008, 47, 919-928. [CrossRef] [PubMed]

19. Ricci-Vitiani, L.; Lombardi, D.G.; Pilozzi, E.; Biffoni, M.; Todaro, M.; Peschle, C.; De Maria, R. Identification and expansion of human colon-cancer-initiating cells. Nature 2007, 445, 111-115. [CrossRef] [PubMed]

20. Zhu, L.; Gibson, P.; Currle, D.S.; Tong, Y.; Richardson, R.J.; Bayazitov, I.T.; Poppleton, H.; Zakharenko, S.; Ellison, D.W.; Gilbertson, R.J. Prominin 1 marks intestinal stem cells that are susceptible to neoplastic transformation. Nature 2009, 457, 603-607. [CrossRef]

21. Kantara, C.; O'Connell, M.R.; Luthra, G.; Gajjar, A.; Sarkar, S.; Ullrich, R.L.; Singh, P. Methods for detecting circulating cancer stem cells (CCSCs) as a novel approach for diagnosis of colon cancer relapse/metastasis. Lab. Investig. 2015, 95, 100-112. [CrossRef]

22. Waki, K.; Yamada, T.; Yoshiyama, K.; Terazaki, Y.; Sakamoto, S.; Matsueda, S.; Komatsu, N.; Sugawara, S.; Takamori, S.; Itoh, K.; et al. PD-1 expression on peripheral blood T-cell subsets correlates with prognosis in non-small cell lung cancer. Cancer Sci. 2014, 105, 1229-1235. [CrossRef]

23. Zhang, W.; Bai, J.F.; Zuo, M.X.; Cao, X.X.; Chen, M.; Zhang, Y.; Han, X.; Zhong, D.R.; Zhou, D.B. PD-1 expression on the surface of peripheral blood $\mathrm{CD} 4^{+} \mathrm{T}$ cell and its association with the prognosis of patients with diffuse large B-cell lymphoma. Cancer Med. 2016, 5, 3077-3084. [CrossRef] [PubMed]

24. Thompson, R.H.; Dong, H.; Lohse, C.M.; Leibovich, B.C.; Blute, M.L.; Cheville, J.C.; Kwon, E.D. PD-1 is expressed by tumor-infiltrating immune cells and is associated with poor outcome for patients with renal cell carcinoma. Clin. Cancer Res. 2007, 13, 1757-1761. [CrossRef]

25. Wu, X.L.; Tu, Q.; Faure, G.; Gallet, P.; Kohler, C.; Bittencourt Mde, C. Diagnostic and Prognostic Value of Circulating Tumor Cells in Head and Neck Squamous Cell Carcinoma: A systematic review and meta-analysis. Sci. Rep. 2016, 6, 20210. [CrossRef] [PubMed]

26. Jatana, K.R.; Balasubramanian, P.; McMullen, K.P.; Lang, J.C.; Teknos, T.N.; Chalmers, J.J. Effect of surgical intervention on circulating tumor cells in patients with squamous cell carcinoma of the head and neck using a negative enrichment technology. Head Neck 2016, 38, 1799-1803. [CrossRef] [PubMed]

27. Sun, T.; Zou, K.; Yuan, Z.; Yang, C.; Lin, X.; Xiong, B. Clinicopathological and prognostic significance of circulating tumor cells in patients with head and neck cancer: A meta-analysis. Oncol. Targets 2017, 10, 3907-3916. [CrossRef]

28. Wang, Z.; Cui, K.; Xue, Y.; Tong, F.; Li, S. Prognostic value of circulating tumor cells in patients with squamous cell carcinoma of the head and neck: A systematic review and meta-analysis. Med. Oncol. 2015, 32, 164. [CrossRef] [PubMed]

29. Tinhofer, I.; Konschak, R.; Stromberger, C.; Raguse, J.D.; Dreyer, J.H.; Johrens, K.; Keilholz, U.; Budach, V. Detection of circulating tumor cells for prediction of recurrence after adjuvant chemoradiation in locally advanced squamous cell carcinoma of the head and neck. Ann. Oncol. 2014, 25, 2042-2047. [CrossRef]

30. Mockelmann, N.; Laban, S.; Pantel, K.; Knecht, R. Circulating tumor cells in head and neck cancer: Clinical impact in diagnosis and follow-up. Eur. Arch. Otorhinolaryngol. 2014, 271, 15-21. [CrossRef]

31. Iinuma, H.; Watanabe, T.; Mimori, K.; Adachi, M.; Hayashi, N.; Tamura, J.; Matsuda, K.; Fukushima, R.; Okinaga, K.; Sasako, M.; et al. Clinical significance of circulating tumor cells, including cancer stem-like cells, in peripheral blood for recurrence and prognosis in patients with Dukes' stage B and C colorectal cancer. J. Clin. Oncol. 2011, 29, 1547-1555. [CrossRef]

32. Bahnassy, A.A.; Zekri, A.R.; El-Bastawisy, A.; Fawzy, A.; Shetta, M.; Hussein, N.; Omran, D.; Ahmed, A.A.; El-Labbody, S.S. Circulating tumor and cancer stem cells in hepatitis C virus-associated liver disease. World J. Gastroenterol. 2014, 20, 18240-18248. [CrossRef] [PubMed]

33. Malara, N.; Trunzo, V.; Foresta, U.; Amodio, N.; De Vitis, S.; Roveda, L.; Fava, M.; Coluccio, M.; Macri, R.; Di Vito, A.; et al. Ex-vivo characterization of circulating colon cancer cells distinguished in stem and differentiated subset provides useful biomarker for personalized metastatic risk assessment. J. Transl. Med. 2016, 14, 133. [CrossRef] [PubMed]

34. Pirozzi, G.; Tirino, V.; Camerlingo, R.; La Rocca, A.; Martucci, N.; Scognamiglio, G.; Franco, R.; Cantile, M.; Normanno, N.; Rocco, G. Prognostic value of cancer stem cells, epithelial-mesenchymal transition and circulating tumor cells in lung cancer. Oncol. Rep. 2013, 29, 1763-1768. [CrossRef] 
35. Skirecki, T.; Hoser, G.; Kawiak, J.; Dziedzic, D.; Domagala-Kulawik, J. Flow cytometric analysis of CD133and EpCAM-positive cells in the peripheral blood of patients with lung cancer. Arch. Immunol. Exp. 2014, 62, 67-75. [CrossRef] [PubMed]

36. Park, B.S.; Jung, S.Y.; Kwon, S.M.; Bae, J.H.; Lee, S.M.; Shin, D.H.; Son, G.M. Comparison of putative circulating cancer stem cell detection between the hepatic portal system and peripheral blood in colorectal cancer patients. Ann. Surg. Treat. Res. 2014, 87, 232-238. [CrossRef]

37. Rentala, S.; Chintala, R.; Guda, M.; Chintala, M.; Komarraju, A.L.; Mangamoori, L.N. Atorvastatin inhibited Rho-associated kinase 1 (ROCK1) and focal adhesion kinase (FAK) mediated adhesion and differentiation of $\mathrm{CD}_{133}{ }^{+} \mathrm{CD} 44^{+}$prostate cancer stem cells. Biochem. Biophys. Res. Commun. 2013, 441, 586-592. [CrossRef] [PubMed]

38. Yang, N.; Jiang, Y.; Zhang, H.; Sun, B.; Hou, C.; Zheng, J.; Liu, Y.; Zuo, P. Active targeting docetaxel-PLA nanoparticles eradicate circulating lung cancer stem-like cells and inhibit liver metastasis. Mol. Pharm. 2015, 12, 232-239. [CrossRef]

39. Hasmim, M.; Badoual, C.; Vielh, P.; Drusch, F.; Marty, V.; Laplanche, A.; de Oliveira Diniz, M.; Roussel, H.; De Guillebon, E.; Oudard, S.; et al. Expression of EPHRIN-A1, SCINDERIN and MHC class I molecules in head and neck cancers and relationship with the prognostic value of intratumoral $\mathrm{CD} 8^{+} \mathrm{T}$ cells. BMC Cancer 2013, 13, 592. [CrossRef]

40. Bergmann, C.; Strauss, L.; Zeidler, R.; Lang, S.; Whiteside, T.L. Expansion of human T regulatory type 1 cells in the microenvironment of cyclooxygenase 2 overexpressing head and neck squamous cell carcinoma. Cancer Res. 2007, 67, 8865-8873. [CrossRef]

41. Balermpas, P.; Rodel, F.; Rodel, C.; Krause, M.; Linge, A.; Lohaus, F.; Baumann, M.; Tinhofer, I.; Budach, V.; Gkika, E.; et al. CD8 ${ }^{+}$tumour-infiltrating lymphocytes in relation to HPV status and clinical outcome in patients with head and neck cancer after postoperative chemoradiotherapy: A multicentre study of the German cancer consortium radiation oncology group (DKTK-ROG). Int. J. Cancer 2016, 138, 171-181. [CrossRef]

42. Pretscher, D.; Distel, L.V.; Grabenbauer, G.G.; Wittlinger, M.; Buettner, M.; Niedobitek, G. Distribution of immune cells in head and neck cancer: $\mathrm{CD} 8^{+} \mathrm{T}$-cells and CD20 $0^{+} \mathrm{B}$-cells in metastatic lymph nodes are associated with favourable outcome in patients with oro- and hypopharyngeal carcinoma. BMC Cancer 2009, 9, 292. [CrossRef]

43. Song, G.; Wang, X.; Jia, J.; Yuan, Y.; Wan, F.; Zhou, X.; Yang, H.; Ren, J.; Gu, J.; Lyerly, H.K. Elevated level of peripheral CD8(+)CD28(-) T lymphocytes are an independent predictor of progression-free survival in patients with metastatic breast cancer during the course of chemotherapy. Cancer Immunol. Immunother. 2013, 62, 1123-1130. [CrossRef] [PubMed]

44. Yang, C.; Cheng, H.; Luo, G.; Lu, Y.; Guo, M.; Jin, K.; Wang, Z.; Yu, X.; Liu, C. The metastasis status and tumor burden-associated CA125 level combined with the CD4/CD8 ratio predicts the prognosis of patients with advanced pancreatic cancer: A new scoring system. Eur. J. Surg. Oncol. 2017, 43, 2112-2118. [CrossRef]

45. Nasr, G.N.; Nasrullayeva, G.; Qaziyev, A.; Al-Ali, J.K. T-Lymphocyte Subset (CD4/CD8) Ratios of Breast Cancer Patients in Basra-Iraq and Baku-Azerbaijan. Asian Pac. J. Cancer Prev.: APJCP 2016, 17, 175-177.

46. Wansom, D.; Light, E.; Worden, F.; Prince, M.; Urba, S.; Chepeha, D.B.; Cordell, K.; Eisbruch, A.; Taylor, J.; D'Silva, N.; et al. Correlation of cellular immunity with human papillomavirus 16 status and outcome in patients with advanced oropharyngeal cancer. Arch. Otolaryngol. Head Neck Surg. 2010, 136, 1267-1273. [CrossRef]

47. Dewyer, N.A.; Wolf, G.T.; Light, E.; Worden, F.; Urba, S.; Eisbruch, A.; Bradford, C.R.; Chepeha, D.B.; Prince, M.E.; Moyer, J. Circulating CD4-positive lymphocyte levels as predictor of response to induction chemotherapy in patients with advanced laryngeal cancer. Head Neck 2014, 36, 9-14. [CrossRef]

48. Lyford-Pike, S.; Peng, S.; Young, G.D.; Taube, J.M.; Westra, W.H.; Akpeng, B.; Bruno, T.C.; Richmon, J.D.; Wang, H.; Bishop, J.A.; et al. Evidence for a role of the PD-1:PD-L1 pathway in immune resistance of HPV-associated head and neck squamous cell carcinoma. Cancer Res. 2013, 73, 1733-1741. [CrossRef]

49. Su, P.J.; Wu, M.H.; Wang, H.M.; Lee, C.L.; Huang, W.K.; Wu, C.E.; Chang, H.K.; Chao, Y.K.; Tseng, C.K.; Chiu, T.K.; et al. Circulating Tumour Cells as an Independent Prognostic Factor in Patients with Advanced Oesophageal Squamous Cell Carcinoma Undergoing Chemoradiotherapy. Sci. Rep. 2016, 6, 31423. [CrossRef] 
50. Chiu, T.K.; Chou, W.P.; Huang, S.B.; Wang, H.M.; Lin, Y.C.; Hsieh, C.H.; Wu, M.H. Application of optically-induced-dielectrophoresis in microfluidic system for purification of circulating tumour cells for gene expression analysis-Cancer cell line model. Sci. Rep. 2016, 6, 32851. [CrossRef] [PubMed]

51. Duncan, L.D.; Winkler, M.; Carlson, E.R.; Heidel, R.E.; Kang, E.; Webb, D. p16 immunohistochemistry can be used to detect human papillomavirus in oral cavity squamous cell carcinoma. J. Oral Maxillofac. Surg. 2013, 71, 1367-1375. [CrossRef] [PubMed]

C 2019 by the authors. Licensee MDPI, Basel, Switzerland. This article is an open access article distributed under the terms and conditions of the Creative Commons Attribution (CC BY) license (http://creativecommons.org/licenses/by/4.0/). 